\title{
Internalisasi Nilai-Nilai Islam dalam Praktik Nengah Sawah pada Masyarakat Terdampak Pembangunan Waduk Jatigede Sumedang
}

\author{
https://doi.org/10.32509/abdimoestopo.v4i02.1579
}

Elis Teti Rusmiati

\author{
Fakultas Ilmu Sosial dan Ilmu Politik Universitas Prof. Dr. Moestopo (Beragama) \\ Jl. Hang Lekir I No. 8, Jakarta, Indonesia
}

Email Korespondensi: elistr@moestopo.ac.id

\begin{abstract}
Abstrak - Hasil penelitian penulis pada bulan Juni 2021 menemukan fakta adanya praktik kerjasama pertanian nengah sawah (bagi hasil) pada masyarakat terdampak pembangunan Waduk Jatigede Sumedang, yang mekanismenya dilakukan berdasarkan tradisi yang diwarisi dari leluhur nenek moyang mereka. Masyarakat terdampak yang seluruhnya beragama Islam ini belum mengenal mengenai pengelolaan lahan pertanian berdasarkan konsep ekonomi Islam. Kegiatan Pengabdian kepada Masyarakat (PkM) ini merupakan tindak lanjut dari hasil penelitian tersebut dengan tujuan untuk memperkenalkan konsep Islam tentang kerjasama (syirkah) dalam praktik pertanian dengan sistem mukhabarah, agar nilai-nilai Islam terinternalisasi dalam praktik nengah sawah tersebut. Kegiatan ini dilakukan melalui tahapan: 1) survey; 2) pembuatan modul; 3) penyuluhan; 4) pendampingan; 5) evaluasi. Hasil kegiatan PkM ini memperlihatkan adanya perubahan signifikan pada pengetahuan peserta dan memahami praktik nengah sawah melalui konsep mukhabarah. Pada tahap pendampingan, masyarakat juga bersedia menginternalisasikan nilai-nilai Islam pada tradisi nengah sawah untuk memastikan bahwa kegiatan tersebut sudah sesuai dengan ajaran Agama Islam. Peserta mulai menyadari bahwa terdapat nilai-nilai luhur humanity dalam Islam yang dapat dikembangkan dalam tradisi nengah sawah yang harus menjadi fokus perhatian.
\end{abstract}

Kata Kunci: Internalisasi Nilai, Mukhabarah, Nengah Sawah, Waduk Jatigede.

Abstract - The results of the author's research June 2021 found the fact that there was a practice of agricultural cooperation of the nengah sawah (profit sharing) in the affected communities in the construction of the Jatigede Sumedang Reservoir, which was mechanism based on the traditions inherited from their ancestors. These Affected Persons, of who are all Muslim, are not familiar with the management of agricultural land based on Islamic economic concepts. This Community Service Activity (PkM) is a follow-up to the results of the research with the aim of introducing the Islamic concept of cooperation (syirkah) in agricultural practice with the mukhabarah system, so that Islamic values are internalized in the practice of nengah sawah. This activity is carried out through the following stages: 1) survey; 2) module creation; 3) counseling; 4) assistance; 5) evaluation. The results of this PkM activity showed a significant change in the participants knowledge and understanding of the practice of nengah sawah through the concept of mukhabarah. At the assistance stage, the community is also willing to internalize Islamic values in the nengah sawah tradition to ensure that these activities are in accordance with the teachings of Islam. Participants began to realize that there are noble values of humanity in Islam that can be developed in the nengah sawah tradition that must be the focus of attention.

Keywords: Internalization of Values, Mukhabarah, Nengah Sawah, Jatigede Reservoir 


\section{PENDAHULUAN}

Nengah Sawah ialah istilah yang digunakan dalam kegiatan praktik kerjasama pertanian antara pemilik lahan/sawah dengan penggarap. Nengah sawah bermakna membagi setengah dari hasil panen sawah yang dikelola, masing-masing untuk pihak pemilik sawah dan pihak penggarap. Istilah Nengah sawah biasa dipakai oleh masyarakat Jawa Barat (suku sunda), adapun di Jawa Tengah atau Jawa Timur dikenal dengan istilah Maro (membagi separo), dan di Banten dikenal dengan istilah Peparon atau Gegaden.

Praktik nengah sawah merupakan tradisi nenek moyang yang bukan hanya tumbuh di Pulau Jawa saja melainkan juga di berbagai daerah di Indonesia yang dikenal sebagai negara agraris. Pemilikan tanah yang sempit dan timpang menjadi penyebab utama tumbuh dan berkembangnya tradisi nengah hingga sekarang.

Tradisi nengah sawah ini bermunculan pada masyarakat yang terdampak (OTD) pembangunan Waduk Jatigede Sumedang, pasca kampung halaman mereka tergenang pembangunan waduk. Meskipun OTD sudah memperoleh uang ganti rugi dari Pemerintah tetapi banyak dari mereka yang tidak mampu membeli lahan/tanah kembali seperti yang dulu pernah mereka miliki sebelum pembangunan waduk. Kondisi ini kemudian menjadi faktor pendorong bertambah banyaknya tradisi nengah sawah.(Muhammad Yusuf Qardawi, 2000)

Beberapa desa di sekitar waduk sebenarnya sudah menyediakan lahan perumahan bagi OTD dengan biaya yang sangat murah, seperti dua lokasi yang berada di Desa Pawenang Kecamatan Wado dan Desa Sirnasari Kecamatan Jatinunggal Kabupaten Sumedang. Hanya saja lokasi tersebut hanya cukup untuk tempat tinggal, sedangkan untuk lahan pertanian/perkebunan OTD harus mengupayakannya sendiri.

Banyak faktor yang turut menyebabkan OTD tidak mampu membeli/memiliki lahan sawah atau kebun untuk bertani di tempat tinggal baru mereka. Di antaranya karena proses pembangunan waduk yang menghabiskan waktu puluhan tahun rencana pembangunan sudah dimulai sejak masa Presiden Soekarno yang berimbas pada tersendatnya distribusi ganti rugi, sehingga masyarakat kesulitan membuat perencanaan keuangan. (Wawancara dengan OTD Koswara di Cipondoh Desa Sirnasari pada 21 Maret 2021 pukul 10.12 WIB).

Dari gambaran ini sebenarnya kerjasama nengah sawah merupakan peluang yang tercipta untuk membangun nilai-nilai kemanusiaan yang sangat dianjurkan Islam. Praktik nengah sawah menjadi sarana untuk saling membantu, toleransi, dan mengikat persaudaraan. hubungan manusia dan manusia, dilandasi oleh nilai saling mengasihi, saling mengasah, dan saling mengasuh, agar tercipta suasana kehidupan sosial yang diwamai keakraban, kerukunan, dan kekeluargaan. Nilai-nilai tersebut, terwujudkan dalam ungkapan silih asih, silih asah, jeung silih asuh.(Makmur et al., 2014)

Dalam konsep Islam nengah sawah dikenal dalam bentuk Mukhabarah sebagai salah satu jenis dalam kerjasama (syirkah) pertanian berdasarkan hukum ekonomi Islam. Mukhabarah adalah akad transaksi kerjasama pengolahan lahan pertanian antara pemilik lahan dan penggarap, di mana pemilik lahan memberikan lahan pertanian kepada penggarap untuk menanami dan memelihara, dengan imbalan pembagian tertentu (persentase) dari hasil panen yang diperoleh. Adapun biaya pengelolaan dan benih yang ditanam berasal dari penggarap.(Hasan, 2018)

Dasar hukum dalam pelaksanaan mukhabarah ini salah satunya ialah al-Quran surat alMaidah (5) ayat 2 yang berbunyi: “...dan tolong-menolonglah kamu dalam (mengerjakan) kebajikan dan takwa, dan jangan tolong-menolong dalam berbuat dosa dan pelanggaran". (Departemen Agama RI, 2010)

Konsep mukhabarah mengharuskan adanya ketentuan-ketentuan hukum dan prinsip yang harus dipenuhi serta diperhatikan dalam mekanisme pelaksanaannya, yaitu: 1) Syarat dan Rukun mukhabarah; 2) Modal dan prinsip-prinsip distribusi pendapatan; 3) Analisis risiko dan upaya-upaya penanggulangannya; 4) Sifat kerjasama dan hikmahnya. (Hasan, 2018). Salah satu 
prinsip utama dalam muzara'ah ini adalah penetapan pembagian hasil di awal akad, di samping persyaratan lainnya.(Rohmana, n.d.)

Kegiatan PkM ini bekerjasama dengan Pemerintah Desa dengan melibatkan ibu-ibu kader Tim Penggerak Pemberdayaan Kesejahteraan Keluarga (TP PKK), yang pada saat kegiatan penelitian sebelumnya juga sudah pernah dilibatkan. TP PKK merupakan mitra kerja pemerintah desa yang berfungsi sebagai fasilitator, perencana, pelaksana, pengendali dan penggerak pada program-program Desa (Permendagri nomor 5 tahun 2007 tentang Penataan Lembaga Kemasyarakatan). Dengan demikian, memilih TP PKK sebagai mitra dalam kegiatan ini, sangat strategis. Untuk diketahui bahwa TP PKK berasal dari (orang yang dipercayakan oleh) RT/RW dalam berbagai kegiatan masyarakat, sehingga membantu memudahkan penulis untuk observasi / survey dan menentukan calon peserta penyuluhan.

Kelompok sasaran dari kegiatan ini ialah masyarakat desa yang memang mayoritas penduduknya bermata pencaharian sebagai petani. Melalui bantuan TP PKK diutamakan memilih calon peserta yang diketahui sebagai pelaku kerjasama nengah sawah, baik sebagai pemilik lahan maupun sebagai petani penggarap.

Adapun tujuan yang ingin dicapai dalam kegiatan ini ialah: Pertama, Menciptakan kemampuan masyarakat desa dalam memahami konsep Islam yang terkait dengan topik kerjasama (syirkah) pertanian khusunya dalam bidang Mukhabarah. Kedua Menciptakan kemampuan masyarakat desa dalam praktik tradisi nengah sawah yang mengintegrasikan nilainilai ajaran Islam di dalamnya.

\section{METODE PELAKSANAAN}

Penelitian ini mengunakan pendekatan studi kasus, yang bertujuan untuk mendeskripsikan suatu satuan analisis secara utuh (biasanya berupa tokoh, suatu keluarga, suatu peristiwa, suatu wilayah, suatu pranata, suatu kebudayaan, suatu komunitas), sebagai satuan yang terintegrasi. (Rohmana, n.d.)

DalamPelaksanaan pengabdian kepada masyarakat ini dilakukan melalui beberapa tahapan yaitu: 1) survey; 2) pembuatan modul; 3) penyuluhan; 4) pendampingan; dan 5) evaluasi. Penjelasan pada setiap tahapan sebagaimana yang terlihat pada tabel berikut ini.

Tabel 1. Tahapan Kegiatan Pengabdian kepada Masyarakat

\begin{tabular}{|c|c|c|c|c|}
\hline \multirow[t]{2}{*}{ No } & \multirow{2}{*}{$\begin{array}{c}\text { Kegiatan dan } \\
\text { Waktu Pelaksanaan }\end{array}$} & \multicolumn{3}{|c|}{ Keterlibatan dalam Kegiatan } \\
\hline & & Dosen & TP PKK & Masyarakat \\
\hline 1 & $\begin{array}{l}\text { Survey dan } \\
\text { pemetaan } \\
\text { kemampuan awal } \\
\text { peserta } \\
\text { 20-21 Maret } 2021\end{array}$ & $\begin{array}{l}\text { Merumuskan } \\
\text { instrumen untuk } \\
\text { mengukur } \\
\text { kemampuan } \\
\text { peserta }\end{array}$ & $\begin{array}{l}\text { Membantu } \\
\text { memberikan } \\
\text { informasi awal } \\
\text { dan data untuk } \\
\text { melengkapi } \\
\text { hasil survey }\end{array}$ & $\begin{array}{l}\text { Masyarakat } \\
\text { menyediakan } \\
\text { waktu dan } \\
\text { tempat untuk } \\
\text { melakukan } \\
\text { survei }\end{array}$ \\
\hline 2 & $\begin{array}{l}\text { Pembuatan Modul } \\
\text { untuk materi } \\
\text { penyuluhan } \\
\text { 22-27 Maret } 2021\end{array}$ & $\begin{array}{l}\text { Pembuatan } \\
\text { konten modul } \\
\text { penyuluhan } \\
\text { berdasarkan hasil } \\
\text { survei }\end{array}$ & $\begin{array}{l}\text { Membantu } \\
\text { verifikasi } \\
\text { modul }\end{array}$ & $\begin{array}{l}\text { Membantu } \\
\text { verifikasi } \\
\text { modul }\end{array}$ \\
\hline 3 & $\begin{array}{l}\text { Penyuluhan } \\
28 \text { Maret } 2021\end{array}$ & $\begin{array}{l}\text { Memberikan } \\
\text { materi }\end{array}$ & $\begin{array}{l}\text { Membantu } \\
\text { berlangsungnya } \\
\text { penyuluhan } \\
\text { dan/atau ikut } \\
\text { sebagai peserta }\end{array}$ & $\begin{array}{l}\text { Masyarakat } \\
\text { mengikuti } \\
\text { penyuluhan }\end{array}$ \\
\hline
\end{tabular}




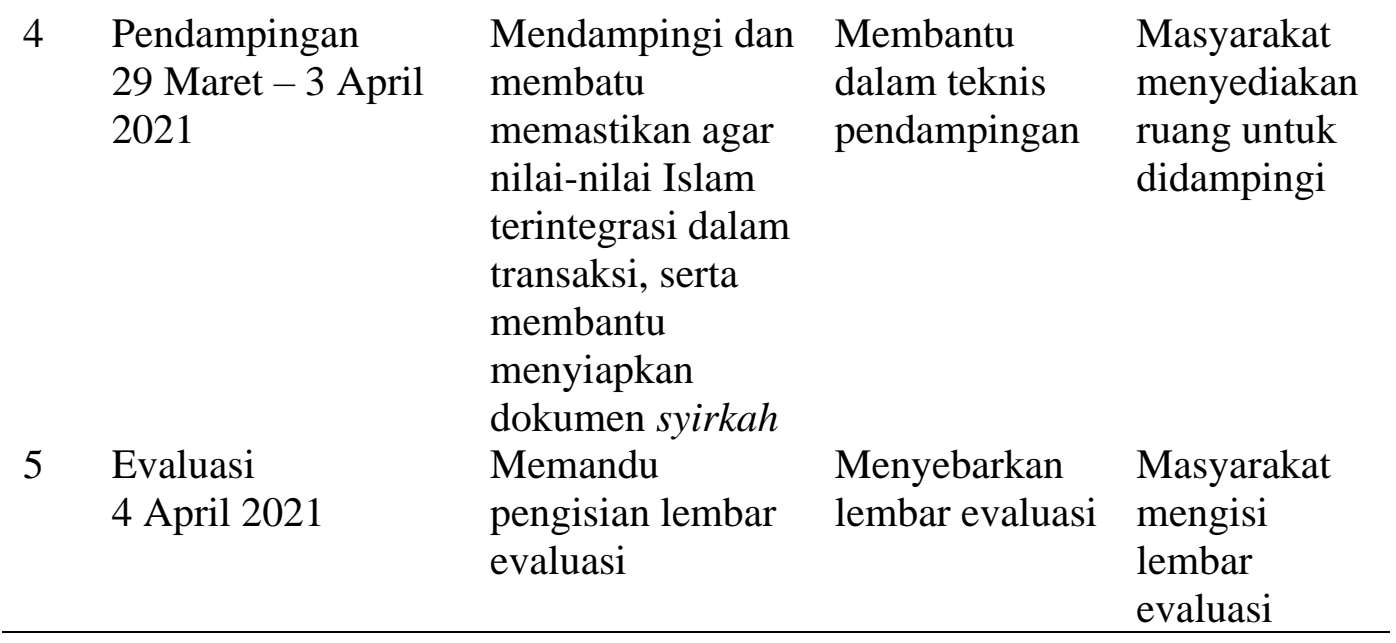

\section{HASIL DAN PEMBAHASAN}

Kegiatan Pengabdian kepada Masyarakat ini dilaksanakan di dua Desa yaitu Desa Sirnasari dan Desa Tarikolot Kecamatan Jatinunggal Kabupaten Sumedang Provinsi Jawa Barat. Lokasi ini dipilih karena merupakan desa penyangga bagi OTD yang lokasinya berdekatan dengan pembangunan Waduk Jatigede dari sisi bagian selatan waduk. Banyak faktor yang mempengaruhi hasil panen dari sawah yang digarap dengan Metode Nengah, misalnya faktor lahan, bibit, pupuk, modal, tenaga kerja, dan lain-lain (Oktaviani, 2019; Rusmiati, 2021)

Adapun waktu pelaksanaan kegiatan ialah mulai 20 Maret sampai dengan 4 April 2021, dengan perincian sebagaimana terlihat pada tabel 1 .

Tahapan awal kegiatan dimulai dengan survey dan observasi lapangan terkait dengan praktik nengah sawah. Pada tahap ini dilakukan juga wawancara ringan untuk mengetahui pemahaman calon peserta tentang konsep kerjasama pengelolaan pertanian dalam Islam. Kerjasama (syirkah) pertanian dalam Islam sebenarnya ada 3 (tiga) bentuk yakni Musaqah, Muzara'ah, dan Mukhabarah. Perbedaan ketiga bentuk ini terletak dalam hal biaya pengelolaan/pemeliharaan dan penyediaan benih. Dari hasil wawancara diketahui bahwa tradisi nengah sawah di lokasi kegiatan adalah bentuk mukhabarah. Kendati penyebutan mukhabarah sendiri asing bagi mereka tetapi praktik pertanian yang mereka lalukan mengarah pada bentuk mukhabarah yakni kerjasama pengelolaan sawah antara pemilik lahan dengan penggarap di mana biaya pengelolaan serta benih yang disediakan berasal dari penggarap. Hasil panennya dibagi masing-masing setengah antara pemilik sawah dengan penggarap, dan dari cara pembagian inilah kemudian muncul sebutan nengah (membagi setengah).

Hasil survey ini kemudian menjadi landasan untuk: 1) menentukan bentuk materi yang pas yaitu mukhabarah; 2) membuat pemetaan kemampuan awal peserta; 3) mengukur kecerdasan/daya tangkap peserta sehingga berpengaruh pada kedalaman penyajian materi/modul penyuluhan.

Tahap kedua ialah pembuatan modul/materi penyuluhan yang berpatokan pada hasil survey di atas. Modul/materi dibuat singkat dan dengan bahasa yang mudah dipahami masyarakat desa yang rata-rata berpendidikan SMP-SMA. Modul ini sebelum diberikan kepada peserta, terlebih dahulu diverifikasi oleh TP PKK untuk memastikan kemampuan peserta dalam mencerna/memahaminya.

Tahap ketiga ialah penyuluhan. Kegiatan ini dilaksanakan gabungan dua desa yang bertempat di kantor serbaguna Desa Tarikolot. Peserta kegiatan terdiri dari 16 orang ditambah dengan 5 orang TP PKK dari dua desa. Pada akhir materi disediakan waktu untuk diskusi dan tanya jawab sebagai teknik pendalaman materi serta cara untuk mengukur kemampuan pemahaman melalui feedback dari peserta. 
Kegiatan PkM ini hampir bersamaan dengan musim tanam padi yakni sekitar MaretApril. Dengan demikian maka melakukan tahapan keempat yaitu tahap pendampingan, bisa sekaligus menjadi rangkaian kegiatan PkM, yang tidak bersamaan dengan waktu penyuluhan.

Awal persiapan nengah sawah dimulai dengan transaksi atau akad atau serah terima. Kegiatan akad merupakan titik yang paling krusial dan sekaligus strategis. Pada tahap inilah yang sebetulnya sangat perlu pendampingan.

Dalam tradisi nengah sawah yang selama ini berlangsung, akad/transaksi cukup dengan lisan dan hanya dengan kata-kata misalnya penggarap mengatakan:

"Kang, cang garap wae sawah ku abdi nyah! Abdi butuh pisan" (Kak, sawahnya saya saja yang menggarap ya! Saya sangat membutuhkan). Kemudian pemilik sawah menjawab: "Nya sok wae ari butuh mah" (Ya silakan kalau memang membutuhkan). (Wawancara dengan Andar Sutandar, Kepala Desa Tarikolot pada 28 Maret 2021, pukul 15.32 WIB).

Percakapan tersebut sudah dianggap sebagai akad yang sah dan mekanisme nengah sawah tidak perlu ada pembahasan lebih lajut lagi. Nengah sawah semata-mata dilakukan berdasarkan rasa saling percaya dan dianggap sudah saling memahami tradisi sebagaimana yang selama ini sudah berlangsung.

Terhadap kondisi ini maka kegiatan pendampingan yang dilakukan ialah melengkapi proses transaksi/akad dengan: Satu, Memastikan syarat sah mukhabarah terpenuhi sebelum dilaksanakan akad. Dua, Memastikan rukun mukhabarah ada/terpenuhi ketika akad berlangsung. Tiga, Membantu menyediakan dokumen perjanjian kerjasama nengah sawah yang disepakati oleh pihak pemilik sawah dan penggarap yang di dalamya memuat: berita acara akad, identitas kedua belah pihak, identitas objek/lokasi dan batas-batas sawah yang digarap, masa berakhirnya akad, risiko dan upaya-upaya penanggulangannya, distribusi pendapatan, saksisaksi.

Tahap keempat, Memastikan seluruh mekanisme tradisi nengah sawah sesuai dengan nilai-nilai ajaran Islam. Dan Tahap kelima ialah tahap evaluasi. Tahap ini dilakukan dengan menyebarkan lembar evaluasi yang harus diisi peserta. Lembar evaluasi ini diantarkan oleh TP PKK ke rumah peserta dengan maksud supaya membatasi peserta tidak keluar rumah karena musim pandemi covid-19.

Dampak kegiatan Pengabdian kepada Masyarakat ini dapat dilihat dari indikator yang tercermin dalam: 1) jawaban tertulis peserta yang tercantum dalam lembar evaluasi. Terjadi peningkatan pengetahuan dalam memahami tradisi nengah sawah yang lebih sesuai dengan mukhabarah dalam konsep Islam; 2) kesediaan menyesuaikan tradisi nengah sawah dengan cara-cara islami sehingga terjadi internalisasi nilai-nilai Islam tanpa menghapus tradisi yg selama ini sudah berjalan.

\section{SIMPULAN}

Berdasarkan kegiatan yang telah dilaksanakan, penulis menyimpulkan bahwa kegiatan PkM yang berjudul Internalisasi Nilai-Nilai Islam dalam Praktik Nengah Sawah pada Masyarakat Terdampak Pembangunan Waduk Jatigede Sumedang ini berjalan efektif dan menghasilkan dampak perubahan yang baik di masyarakat. Hanya saja, karena keterbatasan mobilitas masyarakat terkait kondisi pandemi, kegiatan ini tidak bisa mengikutsertakan peserta dalam jumlah banyak. Terjadi peningkatan pengetahuan dalam memahami tradisi nengah sawah yang lebih sesuai dengan mukhabarah dalam konsep Islam, kesediaan menyesuaikan tradisi nengah sawah dengan cara-cara islami sehingga terjadi internalisasi nilai-nilai Islam tanpa menghapus tradisi yg selama ini sudah berjalan. Dengan demikian, Pelaksanaan PkM ke depan diharapkan dapat diperluas cakupannya, baik dalam jumlah peserta yang terlibat maupun dalam topik PkM yang diselenggarakan. 


\section{Daftar Pustaka}

Departemen Agama RI. (2010). Al-Qur'an dan Terjemahannya. PT. Panca Cemerlang.

Hasan, A. F. (2018). Fiqh Muammalah dari Klasik hingga Kontemporer (Teori dan Praktek). In Research Repository UIN Maulana Malik Ibrahim. http://repository.uinmalang.ac.id/4531/1/fiqh muammalah FULL.pdf

Makmur, A., Harsono, T. D., S., R. A., Purnama, Y., Roswandi, I., Merlina, N., Gufron, A., \& Budiman, H. G. (2014). Kajian Nilai Budaya Lokal Jatigede di Kabupaten Sumedang.

Oktaviani, A. I. (2019). Reduksi Variabel Pengelolaan Sawah Dengan Metode Nengah Berbasis Etnomatematika Menggunakan Analisis Komponen Utama. UNPAD Repository. https://repository.unpad.ac.id/frontdoor/index/index/year/2020/docId/11728

Qardawi, M. Y. (2000). Halal dan haram dalam islam. Perpustakaan DR Sam Ratulangi SDN Percontohan PAM. http://ucs.sulsellib.net//index.php?p=show_detail\&id=163307

Rohmana, A. (n.d.). Dalam Pandangan Hukum Islam. Uinsgd, V(1), 46-58. https://journal.uinsgd.ac.id/index.php/asy-syariah/article/view/4390/pdf

Rusmiati, E. T. (2021). Laporan Hasil Penelitian Tinjauan Islam tentang Kerjasama Bagi Hasil Pertanian pada Masyarakat Terdampak Pembangunan Waduk Jatigede Sumedang. https://repository.moestopo.ac.id/index.php/UPDM 